\title{
Efficiency Analysis of Chinese Science and Technology Finance based on the DEA-Malmquist Model
}

\author{
Song Wang \\ International College, Zhengzhou University, China \\ 1802800266@qq.com
}

\begin{abstract}
Taking the data of financial input and science-technology (S\&T) output of 30 provinces and municipalities in China from 2015 to 2019 as samples, and based on the DEA-Malmquist model, the efficiency of S\&T finance in China is calculated from provincial level and regional level respectively. The results show that the total factor productivity of S\&T finance in China is on the rise from 2015 to 2019, and there are certain differences in the index and decomposition results of S\&T finance in different regions.
\end{abstract}

Keywords: Science and Technology Finance; DEA-Malmquist Model.

\section{Introduction}

As China's economic development enters a new normal, demographic dividend is gradually declining, energy shortage and other issues are increasingly prominent, and the traditional economic development mode has faced a bottleneck stage. Therefore, transforming the economic development mode and promoting innovative economic development is an inevitable way to achieve further economic development under the new situation. The same is true for the financial industry, the mainstay of the modern national economy. Since the 19th National Congress of the Communist Party of China (CPC), China has made many strategic plans to solve the problems of financial innovation development, including the famous "three-step" strategy of innovative country: to become an innovative country in 2020, to become one of the top financial innovative countries in 2030, and to become a world power in scientific and technological innovation in 2050. According to relevant data, in recent years, the $R \& D$ investment intensity of the whole country is on the rise, the number of patent applications accepted in each region and the amount of regional contracts for technology output in the technology market are also on the rise, which confirms the overall good situation of the combination of S\&T and finance in China. However, whether the increase of science and technology input can be better transformed into scientific and technological achievements with the help of finance, how to measure the efficiency level of S\&T finance, and how to improve the efficiency of S\&T finance in China have been increasingly concerned by the academic circle. This paper attempts to measure the efficiency of S\&T finance in China from 2015 to 2019 from the perspective of S\&T finance efficiency, and puts forward relevant policy suggestions to improve the efficiency of S\&T finance according to the final conclusion.

\section{Literature Review}

At present, the science and technology finance research has been very rich. The existing literature research on S\&T finance can be roughly divided into the following aspects: the connotation of S\&T finance, the efficiency of S\&T finance and the impact of S\&T finance.

\subsection{Research on the Connotation of Science and Technology Finance}

In terms of domestic literature, domestic scholars have not unified the definition of the connotation of S\&T finance. Existing literature of science and technology finance set out from the following two aspects: one is from the interaction of S\&T and finance, Yin (2011) argues that finance is the financial capital of science and technology in science and technology innovation, especially in innovation incubator for new technology and innovation of science and technology enterprises and promoting 
industrialization of high and new technology as the content of financial activities [1]. The other is starting from the system formed by S\&T and finance, Zhao et al. (2009) believe that science and technology finance is a systematic and innovative arrangement of a series of financial instruments, financial systems, financial policies and financial services to promote scientific and technological development, achievement transformation and the development of high-tech industry. It is a system composed of the government, enterprises, market and social intermediary institutions that provide financial resources for scientific and technological innovation activities [2]. The conclusion of the former research perspective is usually regarded as the narrow connotation of S\&T finance, while the latter research perspective is generally regarded as the broad connotation of S\&T finance. With the progress of science and technology and the deep combination of science and technology with finance, the boundary of science and technology finance is further expanding, and the broad definition of science and technology finance is increasingly recognized and applied.

\subsection{Efficiency Study of Science and Technology Finance}

The research on the efficiency of S\&T finance has also been paid attention to by the academic circle. Many academic elites have carried out relevant researches on the efficiency of S\&T finance and obtained many beneficial conclusions. The existing literatures on the efficiency of S\&T finance can be roughly carried out from the following two angles. The first one is the efficiency measurement of S\&T finance. Du et al. (2016) construct output and input indicators of S\&T finance, use the threestage DEA model to measure the efficiency of S\&T finance of all provinces and cities in China, evaluate the efficiency of S\&T finance of all provinces and cities and put forward relevant policy suggestions [3]. From the perspective of the comparison of S\&T financial efficiency in different regions. What's more, Gan et al. (2017) analyzes the difference of S\&T financial efficiency in three economic circles of Bohai Rim, Yangtze River Delta and Pearl River Delta through empirical research, with exploring the reasons for the difference of S\&T financial efficiency in these three regions [4]. From the measurement of S\&T finance efficiency of an economic entity, Feng et al. (2021) calculates the S\&T finance efficiency of small and medium-sized listed enterprises in the National Equities Exchange and Quotations, analyzing the heterogeneity of the efficiency [5]. The second is the research on the influencing factors of the efficiency of S\&T finance. Xue et al. (2017) finds through empirical analysis that financial investment in science and technology and the amount of capital raised in the science and technology capital market can improve the efficiency of S\&T finance, while the amount of bank science and technology credit has a significant negative effect on the efficiency of S\&T finance [6].

\subsection{Research on the Impact of Science and Technology Finance}

The influence of S\&T finance is one of the hot topics in academic circle in recent years. Many literatures have been developed from different perspectives, and many detailed and meticulous researches have been made on the influence of sci-tech finance with some beneficial discussions. The existing literatures on the impact of S\&T finance can be roughly divided into the following aspects: The one is the impact of S\&T finance on economic development. Zhang et al. (2019) conducts an empirical study based on spatial econometric methods and spatial panel data as well as the comprehensive evaluation index system for the development level of S\&T finance, concluding that the input of S\&T finance resources has a significant role in promoting regional economic growth [7]. The other researches are about the impact of S\&T finance on technology innovation. Zhang et al. (2015) conducts an empirical analysis by combining static and dynamic panel data models and analyzes that S\&T financial input could significantly promote technology innovation in the short term, but the effect is not obvious in the long term [8]. 


\section{Present Situation of National S\&T Finance Input and Output}

In December 2010, the Ministry of Science and Technology, the People's Bank of China, the China Securities Regulatory Commission and the China Banking and Insurance Regulatory Commission jointly issued the Notice on Printing and Distributing the Pilot Implementation Plan for Promoting the Integration of Science and Technology and Finance (No.720, 2010), in order to promote the integration and development between S\&T and finance as well as the innovative development of the economy. Later, under the requirements of this document, all provinces in China formulated specific methods to promote the combination of science and technology with finance and paid more attention to the input and output of the development of S\&T and finance. For example, on the basis of in-depth research on the interactive development of S\&T and finance, Henan province established the special fund for science and finance guidance and the venture capital fund for science and technology innovation in 2013 and 2015 respectively to promote the development of science and finance. In 2017, Anhui province issued the Fund Management Measures for Major Science and Technology Projects in Anhui province, standardizing the management and use of funds for major science and technology projects in the province.

\subsection{Present Situation of National Investment in S\&T Finance}

From the overall investment status of science and technology finance in China (As shown in Table 1: Current Investment Status of Science and technology Finance from 2015 to 2019), the internal expenditure of R\&D funds in China was nearly 1.42 trillion yuan in 2015, and this figure rose to about 22.14 trillion yuan in 2019, with an average annual growth rate of about $9.34 \%$. In 2015 , the full-time equivalent of R\&D personnel in China was 3.757 million people per year, while in 2019, the full-time equivalent of R\&D personnel reached 4.799 million people per year, with an annual growth rate of 5.01 percent. This shows that China's investment in science and technology finance is on the rise from 2015 to 2019.

Table 1. Current Investment Status of Science and Technology Finance from 2015 to 2019

\begin{tabular}{|c|c|c|}
\hline Year & $\begin{array}{c}\text { Internal Expenditure of Research and } \\
\text { Experimental Development (R\&D) } \\
\text { Expenditure(ten thousand yuan) }\end{array}$ & $\begin{array}{c}\text { Research and Experimental Development } \\
\text { (R\&D) personnel full-time } \\
\text { equivalent(person/year) }\end{array}$ \\
\hline 2015 & 141667604.70 & 3757717.60 \\
\hline 2016 & 156745300.50 & 3876931.50 \\
\hline 2017 & 176032645.20 & 4032351.00 \\
\hline 2018 & 196742229.30 & 4379876.20 \\
\hline 2019 & 221392428.50 & 4799018.60 \\
\hline
\end{tabular}

From the perspective of the investment in science and technology finance of all provinces and cities in China, in terms of the absolute amount of investment in science and technology finance of all provinces in China, Guangdong province and Jiangsu Province had the highest cumulative investment in S\&T finance from 2015 to 2019, with the internal expenditure of R\&D funds reaching 1.198 trillion yuan and 1.137 trillion yuan respectively. The full-time equivalent of R\&D personnel was 3.1486 million years and 2.8193 million years, respectively. But Qinghai, Xinjiang and other western provinces had less accumulative investment in science and technology finance. From 2015 to 2019, Guizhou, Jiangxi and Fujian saw the fastest annual growth rate of internal R\&D expenditure, reaching $18.35 \%$ and $17.28 \%$, respectively. Jiangxi province had the fastest annual growth rate of full-time equivalent of R\&D personnel, reaching $17.80 \%$.

\subsection{National Science and Technology Finance Output Status Quo}

From the overall investment situation of science and technology finance in China (as shown in Table 2: The Actuality of Science and technology Finance in China from 2015 to 2019), the number of patent applications accepted in 2015 was about 2,616,400, while the number of patent applications 
accepted in 2019 was about 4.17 million, with an average annual growth rate of $9.77 \%$. In 2015 , the value of technology export regional contracts in the national technology market was about 936.83 billion yuan, while in 2019, the value of technology export regional contracts in the national technology market had reached 2.175 trillion yuan, with an average annual growth rate of about $18.35 \%$. This showed that the overall output of science and technology finance in China was on the rise from 2015 to 2019.

Table 2. The Actuality of Science and Technology Finance in China from 2015 to 2019

\begin{tabular}{|c|c|c|}
\hline Year & $\begin{array}{c}\text { Number of patent applications } \\
\text { accepted (pieces) }\end{array}$ & $\begin{array}{c}\text { Technology market technology export contract amount } \\
\text { (ten thousand yuan) }\end{array}$ \\
\hline 2015 & 2616374 & 93683222.20 \\
\hline 2016 & 3280506 & 109308716.72 \\
\hline 2017 & 3512177 & 129205909.12 \\
\hline 2018 & 4120006 & 171372065.81 \\
\hline 2019 & 4170183 & 217482829.44 \\
\hline
\end{tabular}

From the output of science and technology finance of all provinces and cities in China, in terms of the absolute amount of the output of science and technology finance of all provinces in China, from 2015 to 2019, Guangdong province received the highest cumulative number of patent applications, about 3.09 million, and Beijing city received the highest cumulative contract amount of technology export region in the technology market, nearly 600 billion yuan. The output level of science and technology and finance in western provinces such as Qinghai and Xinjiang are still at a lower level in China. From 2015 to 2019, Hainan and Jiangxi province had the highest annual growth rate of patent application acceptance, reaching $24.36 \%$ and $19.89 \%$, respectively, while Jilin and Guangxi province had the highest annual growth rate of technology export regional contract amount, reaching $78.09 \%$ and $60.36 \%$, respectively.

\section{An Empirical Analysis of the Operational Efficiency of Science and Technology Finance in All Provinces of China}

\subsection{Introduction of Model}

DEA model was first proposed by Charnes and Rhoder [9], which is applicable to evaluate the relative effectiveness of the same economic sector. DEA model can be divided into CCR(Charnes-Cooper-Rhodes) model and BCC(Banker-Charnes-Cooper) model according to the characteristics of change and invariance of return to scale, which respectively represent the situation of constant return to scale and variable return to scale. According to the operation and development law of S\&T industry and finance industry, the BCC model with variable return to scale is selected to analyze the efficiency of science and technology finance in China from 2015 to 2019. The corresponding DEA model is as follows:

$$
\min \theta-\varepsilon\left(\hat{e}^{T} S^{-}+e^{T} S^{+}\right) \text {s.t. }\left\{\begin{array}{c}
\sum_{j=1}^{n} X_{j} \lambda_{j}+S^{-}=\theta X_{0} \\
\sum_{j=1}^{n} Y_{j} \lambda_{j}-S^{+}=Y_{0} \\
\sum_{j=1}^{n} \lambda_{j}=1 \\
\lambda_{j} \geq 0, S^{-}, S^{+} \geq 0, j=1,2,3 \ldots
\end{array}\right.
$$

Where, $\mathrm{j}=1,2, \ldots, \mathrm{n}$ represents decision making unit (DMU); $X_{j}$ and $Y_{j}$ are input and output vectors respectively. $\lambda \mathrm{j}$ is the combination of unit coefficients; $\theta$ is efficiency evaluation value; $S^{-}$and $S^{+}$ are the relaxation variables. DEA model is a linear programming problem in essence, and its formula meaning is as follows: if $\theta=1, S^{+}=S^{-}=0$, it indicates that DEA (data enveloping analysis) model is 
relatively effective to calculate efficiency, while $\theta=1, S^{+} \neq 0$, or $S^{-} \neq 0, \theta<1$, the calculated efficiency value is relatively invalid. The efficiency measured by BCC model is decomposed into scale efficiency and technical efficiency based on CRR model. If the corresponding efficiency value is 1 , it reflects that DEA model is relatively effective to calculate the efficiency value. Otherwise, it indicates that the efficiency is relatively ineffective, and the corresponding input or output needs to be changed to achieve the relative efficiency of DEA.

The traditional DEA model can only make a horizontal comparison of DMU in a single year, but cannot analyze the efficiency over the years, and cannot understand the dynamic efficiency changes of DMU in different years in detail. Malmquist model can evaluate the productivity changes of DMU in different years and further analyze the causes of productivity changes, which is mainly used for the comparison of DMU in consecutive years.

Malmquist productivity change index model is:

$$
\begin{gathered}
\mathrm{M}_{0}^{\mathrm{t}+1}=\left[\frac{\mathrm{D}^{\mathrm{t}}\left(\mathrm{x}_{0}^{\mathrm{t}+1}, \mathrm{y}_{0}^{\mathrm{t}+1}\right)}{\mathrm{D}^{\mathrm{t}}\left(\mathrm{x}_{0}^{\mathrm{t}}, \mathrm{y}_{0}^{\mathrm{t}}\right)} \times \frac{\mathrm{D}^{\mathrm{t}+1}\left(\mathrm{x}_{0}^{\mathrm{t}+1}, \mathrm{y}_{0}^{\mathrm{t}+1}\right)}{\mathrm{D}^{\mathrm{t}+1}\left(\mathrm{x}_{0}^{\mathrm{t}}, \mathrm{y}_{0}^{\mathrm{t}}\right)}\right]^{\frac{1}{2}}=\frac{\mathrm{D}^{\mathrm{t}+1}\left(\mathrm{x}_{0}^{\mathrm{t}+1}, \mathrm{y}_{0}^{\mathrm{t}+1}\right)}{\mathrm{D}^{\mathrm{t}}\left(\mathrm{x}_{0}^{\mathrm{t}}, \mathrm{y}_{0}^{\mathrm{t}}\right)} \times\left[\frac{\mathrm{D}^{\mathrm{t}}\left(\mathrm{x}_{0}^{\mathrm{t}+1}, \mathrm{y}_{0}^{\mathrm{t}+1}\right)}{\mathrm{D}^{\mathrm{t}+1}\left(\mathrm{x}_{0}^{\mathrm{t}+1}, \mathrm{y}_{0}^{\mathrm{t}+1}\right)} \times \frac{\mathrm{D}^{\mathrm{t}}\left(\mathrm{x}_{0}^{\mathrm{t}}, \mathrm{y}_{0}^{\mathrm{t}}\right)}{\mathrm{D}^{\mathrm{t}+1}\left(\mathrm{x}_{0}^{\mathrm{t}}, \mathrm{y}_{0}^{\mathrm{t}}\right)}\right]^{\frac{1}{2}} \\
\text { tfpch }=\text { effch } \times \text { techch }=\text { pech } \times \text { sech } \times \text { techch }
\end{gathered}
$$

Where, $D^{t}\left(\chi_{0}^{t}, \gamma_{0}^{t}\right)$ is the ratio of the maximum and minimum value of the $t$ phase, that is, the distance from the actual value to the front surface. When $M_{0}^{t+1}>1$, it represents productivity increase; When $M_{0}^{t+1}<1$, it represents the decrease of productivity; When $M_{0}^{t+1}=1$, it means productivity is constant. Effch stands for technological change, techch is for technological progress, Pech represents for pure technical efficiency, SECH is for scale efficiency, and TFPCH is on behalf of total factor productivity. Total factor productivity can be measured from two aspects: technological change and technological progress. Technological change is composed of pure technical efficiency and scale efficiency.

\subsection{Empirical Test on the Efficiency of Science and Technology Finance in China}

\subsubsection{Selection of Relevant Indicators and Data Sources}

In this paper, the efficiency of S\&T finance in provinces and cities across the country is measured from two aspects: input and output of S\&T finance (as shown in Table 3: National S\&T Finance Efficiency Evaluation Index System). From the aspect of investment in S\&T finance, on the basis of the research on S\&T finance investment by referring to relevant literature $[10,11]$, the internal expenditure of $R \& D$ funds and full-time equivalent of $R \& D$ personnel are selected to evaluate the overall investment in S\&T finance of all provinces and cities in China. From the output of S\&T finance, the output level of S\&T finance in the R\&D stage and application stage is measured by the number of patents accepted by provinces or cities and the amount of technology export contracts in the technology market. Based on the DEA-Malmquist model, this paper takes the data of financial input and S\&T output of all provinces and cities in China (except Hong Kong, Macao and Taiwan) from 2015 to 2019 as samples to analyze the efficiency of S\&T finance of all provinces and cities in China.

Table 3. National S\&T Finance Efficiency Evaluation Index System

\begin{tabular}{|c|c|c|}
\hline $\begin{array}{c}\text { First level indic } \\
\text { ators }\end{array}$ & Second level indicators & $\begin{array}{c}\text { Index } \\
\text { variables }\end{array}$ \\
\hline \multirow{2}{*}{ Input indicators } & Internal expenditure of R\&D expenditure/ten thousand yuan & $X_{1}$ \\
\cline { 2 - 3 } & Full time equivalent of R\&D personnel /person*year & $X_{2}$ \\
\hline \multirow{2}{*}{$\begin{array}{c}\text { Output } \\
\text { indicators }\end{array}$} & Number of patent applications accepted /unit & $Y_{1}$ \\
\cline { 2 - 3 } & $\begin{array}{c}\text { the amount of regional contracts for technology output in the technology } \\
\text { market / ten thousand yuan }\end{array}$ & $Y_{2}$ \\
\hline
\end{tabular}


In order to study the efficiency of S\&T finance in all provinces and cities in China more accurately, all provinces and cities in China are selected as independent decision-making unit. The data of the above indicators come from China S\&T Statistical Yearbook and China Statistical Yearbook. The above data should be processed in advance before the specific analysis of the efficiency of S\&T finance in various provinces and cities in China. Since the data of the regional contract amount index of technology output in the technology market of Tibet in most years are missing in relevant materials and databases, the index data of Tibet is removed and the remaining 30 provinces and cities are left for analysis as decision making units. And because the data of some provinces in some years are not included in relevant statistics, Excel is used to reasonably calculate and obtain the complete data of four indicators, including internal expenditure of R\&D funds, full-time equivalent of R\&D personnel, number of patent acceptance and regional contract amount of technology output in technology market, in 30 provinces and cities (except Xizang, Hong Kong, Macao and Taiwan) from 2015 to 2019.

\subsubsection{Empirical Test}

After being processed, the indicators above are put into the formula and processed by DEAP2.1 software, and the results are as follows (as shown in Table 4 and Table 6):

It can be seen from Table 4 that during the five years from 2015 to 2019, from the perspective of the average of all indicators listed in the table, the national average TFP index of S\&T was greater than 1, indicating that the TFP of science and technology finance was on the rise from 2015 to 2019. Among the 30 provinces and cities in China, 25 provinces and cities had TFP greater than 1, and only Beijing, Tianjin, Hebei, Shanxi and Neimenggu have TFP less than 1. Among them, Henan province had the fastest annual growth rate of S\&T financial TFP, with an annual growth rate of $48.2 \%$, while Neimenggu had the lowest and negative annual growth rate of S\&T financial TFP, which was $-23.7 \%$. Ranking the TFP index of science and technology finance of 30 provinces and cities in China, we could obtain four echelons, as shown in Table 5. As can be seen from Table 3, Henan, Hubei, Guangdong and Hunan were in the first tier, while the five provinces with TFP less than 1 were in the fourth tier, and the other provinces and cities were in the second and third tier.

According to the above statistical description of the TFP index and its decomposition index of S\&T finance of all provinces in China from 2015 to 2019, the high TFP index of S\&T finance of Henan, Hubei, Guangdong and Hunan indicates that the growth rate of total factor productivity of science and technology finance of these regions is high from 2015 to 2019 . There are several reasons for the high growth rate of TFP in these regions. First, local governments provide policy support for TFP. For example, local organizations hosted the "Northern gulf city cooperation of S\&T and financial innovation conference" in 2016 in Guangdong province. The conference fully listened to experts' opinions and discussions on the integration mechanism of S\&T and finance and the development strategy of science and finance, which provided theoretical basis and intellectual support for the development and construction of science and finance in northern gulf region of Guangdong Province. Second, the local economy and financial foundation is relatively weak, with rapid growth supported by favorable factors such as policy support. For example, Henan's financial added value accounted for only $4.35 \%$ of GDP in 2015 , far lower than the national average of $7.5 \%$, showing that its financial development foundation is relatively weak.

According to the scale efficiency of S\&T finance in all provinces and cities above, the national average scale efficiency of S\&T finance was greater than 1, which manifests that, on the whole, the scale efficiency of S\&T finance had a certain upward trend from 2015 to 2019 . All the 30 provinces and cities in China were between 0.931 and 1.129 (as shown in Figure 1). The scale efficiency index of sci-tech finance in 11 provinces and cities were higher than the average of 1.01, among which Henan province and Guizhou Province, having higher scale efficiency index of sci-tech finance were both higher than 1. What's more, Hunan province had scale efficiency equal to 1 . The scale efficiency index reflected the management level of S\&T finance of each region. Therefore, the above data also showed that Henan, Guizhou and Hunan provinces had a high management level of S\&T finance. 
Volume 17 (2022)

Table 4. Comprehensive Efficiency and Decomposition Results of S\&T Finance by Provinces in

China from 2015 to 2019

\begin{tabular}{|c|c|c|c|c|c|}
\hline Region & $\begin{array}{l}\text { Technical } \\
\text { efficiency } \\
\text { index }\end{array}$ & $\begin{array}{l}\text { Technological } \\
\text { progress index }\end{array}$ & $\begin{array}{l}\text { Purely technical } \\
\text { efficiency index }\end{array}$ & $\begin{array}{c}\text { Scale } \\
\text { efficiency } \\
\text { index }\end{array}$ & $\begin{array}{c}\text { Total factor } \\
\text { productivity(TFP) index }\end{array}$ \\
\hline Beijing & 0.888 & 0.995 & 0.895 & 0.992 & 0.884 \\
\hline Tianjin & 0.891 & 0.931 & 0.908 & 0.981 & 0.83 \\
\hline Hebei & 0.892 & 0.896 & 0.922 & 0.968 & 0.799 \\
\hline Shanxi & 0.908 & 0.881 & 0.946 & 0.959 & 0.8 \\
\hline Neimenggu & 0.869 & 0.879 & 0.908 & 0.957 & 0.763 \\
\hline Liaoning & 0.976 & 1.141 & 1.036 & 0.942 & 1.113 \\
\hline Jilin & 0.905 & 1.149 & 0.963 & 0.94 & 1.04 \\
\hline Heilongjiang & 0.981 & 1.099 & 1.022 & 0.959 & 1.078 \\
\hline Shanghai & 0.931 & 1.131 & 0.987 & 0.943 & 1.053 \\
\hline Jiangsu & 0.931 & 1.115 & 1 & 0.931 & 1.037 \\
\hline Zhejiang & 1.01 & 1.123 & 1.027 & 0.983 & 1.134 \\
\hline Anhui & 1.044 & 1.102 & 1.048 & 0.996 & 1.15 \\
\hline Fujian & 1.102 & 1.081 & 1.102 & 1.001 & 1.192 \\
\hline Jiangxi & 1.055 & 1.043 & 1.047 & 1.008 & 1.1 \\
\hline Shandong & 1.002 & 1.042 & 0.992 & 1.01 & 1.044 \\
\hline Henan & 1.129 & 1.313 & 1 & 1.129 & 1.482 \\
\hline Hubei & 1.057 & 1.34 & 0.993 & 1.064 & 1.416 \\
\hline Hunan & 1.052 & 1.289 & 0.957 & 1.1 & 1.356 \\
\hline Guangdong & 1.077 & 1.263 & 1.008 & 1.068 & 1.36 \\
\hline Guangxi & 1.015 & 1.053 & 0.99 & 1.025 & 1.069 \\
\hline Hainan & 1.175 & 1.006 & 1.097 & 1.071 & 1.183 \\
\hline Chongqing & 1.197 & 1.026 & 1.125 & 1.064 & 1.228 \\
\hline Sichuan & 1.158 & 1.052 & 1.056 & 1.096 & 1.219 \\
\hline Guizhou & 1.043 & 1.071 & 0.938 & 1.113 & 1.117 \\
\hline Yunnan & 0.932 & 1.073 & 0.894 & 1.043 & 1 \\
\hline Shanxi & 1.1 & 1.016 & 1.098 & 1.003 & 1.118 \\
\hline Gansu & 1.062 & 1.023 & 1.06 & 1.003 & 1.087 \\
\hline Qinghai & 1.117 & 1.015 & 1.12 & 0.998 & 1.134 \\
\hline Ningxia & 1.036 & 1.043 & 1.039 & 0.997 & 1.08 \\
\hline Xinjiang & 1.061 & 1.039 & 1.059 & 1.002 & 1.103 \\
\hline Average & 1.016 & 1.069 & 1.006 & 1.01 & 1.085 \\
\hline
\end{tabular}

Table 5. TFP Index Ranking of 30 Provinces and Cities in China

\begin{tabular}{|c|c|c|c|}
\hline $\begin{array}{c}\text { Tier 1 } \\
(\geq 1.3)\end{array}$ & $\begin{array}{c}\text { Tier 2 } \\
(\geq 1.1 \text { and }<1.3)\end{array}$ & $\begin{array}{c}\text { Tier 3 } \\
(\geq 1 \text { and }<1.3)\end{array}$ & $\begin{array}{c}\text { Tier 4 } \\
(<1)\end{array}$ \\
\hline & Chongqing, Sichuan, & & \\
& Fujian, Hainan, & Gansu, Ningxia, & Beijing, Tianjin, \\
Henan, Hubei, & Anhui, Zhejiang, & Heilongjiang, Guangxi, & Shanxi, Hebei, \\
Guangdong, Hunan & Qinghai, Shaanxi, & Shanghai, Shandong, Jilin, Jiangsu, & Neimenggu \\
& Guizhou, Liaoning, & Yunnan & \\
& Xinjiang, Jiangxi & & \\
\hline
\end{tabular}




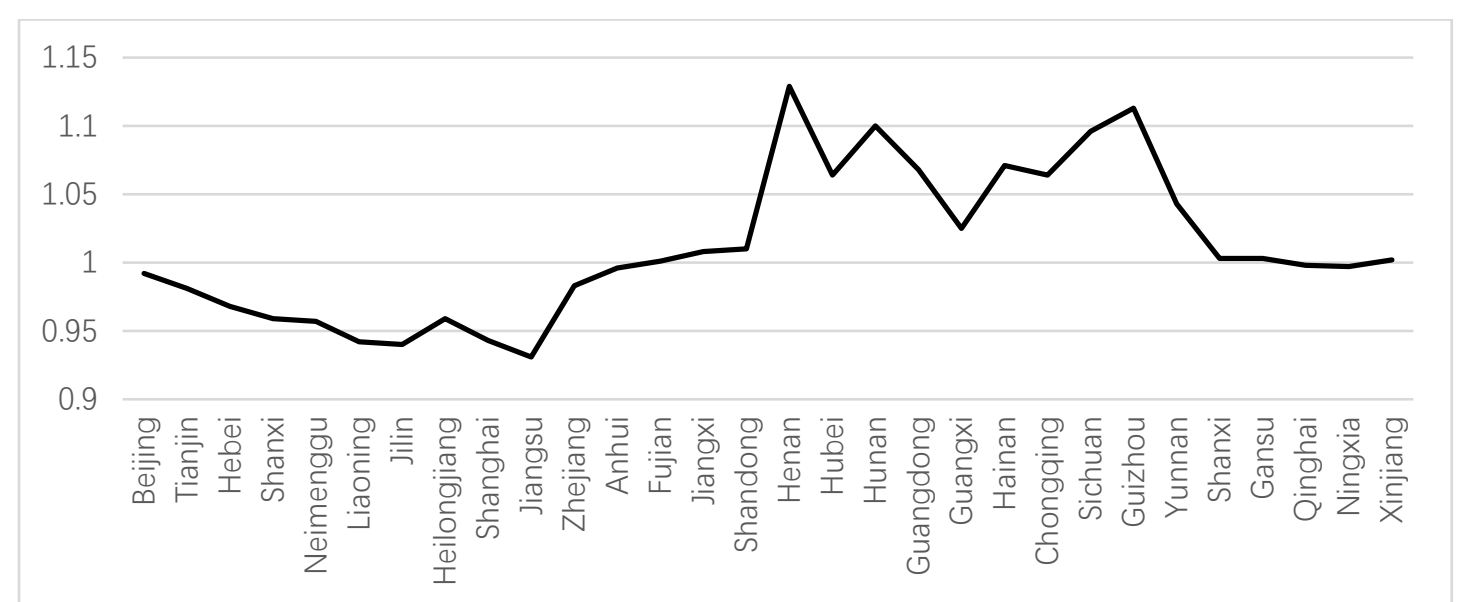

Fig 1. Comparison Chart of Scale Efficiency Index of S\&T Finance in 30 Provinces and Cities in China

According to the above results, the national average technological progress index of S\&T finance was 1.069, and the technological progress index of S\&T finance was higher than 1 in most provinces and cities. Only Beijing, Tianjin, Hebei, Shanxi and Neimenggu had the technological progress index less than 1. This showed that during the period of 2015-2019, the technological and financial technology level in most regions of China was on the rise.

Table 6. Comprehensive Efficiency of S\&T Finance and its Decomposition Results of Provinces and Cities in China from 2015 to 2019

\begin{tabular}{|c|c|c|c|c|c|}
\hline Year & $\begin{array}{c}\text { Technical } \\
\text { efficiency } \\
\text { index }\end{array}$ & $\begin{array}{c}\text { Technological } \\
\text { progress index }\end{array}$ & $\begin{array}{c}\text { Purely technical } \\
\text { efficiency index }\end{array}$ & $\begin{array}{c}\text { Scale efficiency } \\
\text { index }\end{array}$ & $\begin{array}{c}\text { Total factor } \\
\text { productivity(TFP) index }\end{array}$ \\
\hline $2015-2016$ & 1.043 & 1.308 & 1.051 & 0.993 & 1.364 \\
\hline $2016-2017$ & 1.011 & 0.797 & 0.975 & 1.037 & 0.805 \\
\hline $2017-2018$ & 0.908 & 1.348 & 1.036 & 0.877 & 1.224 \\
\hline $2018-2019$ & 1.112 & 0.929 & 0.964 & 1.154 & 1.033 \\
\hline Average & 1.016 & 1.069 & 1.006 & 1.010 & 1.085 \\
\hline
\end{tabular}

Table 6 showed the comprehensive efficiency of S\&T finance and its decomposition results of provinces and cities in China from 2015 to 2019. It can be seen that the TFP of S\&T finance in China from 2015 to 2019 was greater than 1, indicating that the TFP of S\&T finance in China from 2015 to 2019 was on the rise. From 2015 to 2016, the growth rate was the fastest, reaching $36.4 \%$, while from 2016 to 2017, the growth rate was the slowest, with a downward trend. According to the decomposition results of S\&T finance in all provinces and cities in China from 2015 to 2019, the technical efficiency index, technological progress index, pure technical efficiency index and scale efficiency index were all greater than 1, which also illustrated the good development trend of S\&T finance in China from 2015 to 2019.

Compare the average value of comprehensive index and decomposition result of S\&T and finance efficiency in different regions of China (Table 7). From the TFP index of S\&T and finance, the four regions were all above 1 . Among them, the central region had the highest TFP, representing the highest annual growth rate of S\&T efficiency, reaching $21.7 \%$, while the eastern region had the lowest annual growth rate, reaching 5.2\%. According to the technical efficiency index of S\&T finance of different regions in China, the average technical efficiency of S\&T finance of the four regions were between 0.99 and 1.06, and the western region was the highest, reaching 1.054. From the perspective of the S\&T financial technological progress index of different regions in China, the average value of S\&T financial technological progress index of the four regions was above 1, and the highest value was 1.161 in the central region. According to the pure technical efficiency index of S\&T finance in 
the four regions of China, the pure technical efficiency in the eastern and central regions was below 1 , while the pure technical efficiency in the western and northeastern regions was above 1 . The eastern region was the lowest with 0.994 , and the western region was the highest with 1.026 . According to the scale efficiency index of S\&T finance in different regions of China, the scale efficiency index of S\&T finance in eastern and northeast China was below 1, and the scale efficiency index of S\&T finance in central and western China were above 1. The scale efficiency index of S\&T finance in northeast China was the lowest, while that in central China was the highest.

Table 7. Average Value of Comprehensive Efficiency and Decomposition Result of S\&T Finance Efficiency of Different Regions in China from 2015 to 2019

\begin{tabular}{|c|c|c|c|c|c|}
\hline Region & $\begin{array}{c}\text { Technical } \\
\text { efficiency index }\end{array}$ & $\begin{array}{c}\text { Technological } \\
\text { progress index }\end{array}$ & $\begin{array}{c}\text { Purely technical } \\
\text { efficiency index }\end{array}$ & $\begin{array}{c}\text { Scale } \\
\text { efficiency } \\
\text { index }\end{array}$ & $\begin{array}{c}\text { Total factor } \\
\text { productivity(TFP) index }\end{array}$ \\
\hline $\begin{array}{c}\text { Eastern } \\
\text { region }\end{array}$ & 0.990 & 1.058 & 0.994 & 0.995 & 1.052 \\
\hline Middle region & 1.041 & 1.161 & 0.999 & 1.043 & 1.217 \\
\hline $\begin{array}{c}\text { Western } \\
\text { region }\end{array}$ & 1.054 & 1.026 & 1.026 & 1.027 & 1.083 \\
\hline $\begin{array}{c}\text { North-eastern } \\
\text { region }\end{array}$ & 0.954 & 1.130 & 1.007 & 0.947 & 1.077 \\
\hline
\end{tabular}

\section{Research Conclusions and Policy Suggestions}

Based on the literature on S\&T finance, this paper sorts out the concept, efficiency and impact of S\&T finance, and analyzes the input and output of S\&T finance in all provinces of China from 2015 to 2019. Using the DEA-Malmquist model, the internal expenditure of R\&D funds, full-time equivalent of $R \& D$ personnel, the number of patent applications accepted and the number of regional contracts of technology output in technology market are selected as indicators to measure the efficiency of S\&T finance, and the efficiency of S\&T finance in each 30 provinces and cities in China from 2015 to 2019 is estimated. The final conclusions are as follows. First of all, from 2015 to 2019, the input-output efficiency of S\&T finance in 30 provinces and cities gradually increased, indicating that the overall development trend of S\&T finance in China is good. Secondly, the average efficiency of S\&T finance in 30 provinces and cities was relatively high from 2015 to 2019, and only a few provinces and cities had S\&T financial TFP less than 1. Thirdly, from the perspective of time trend, the TFP of S\&T finance of 30 provinces and cities in China grew fastest from 2015 to 2016, while the growth rate slowed down from 2015 to 2019. Last but not least, from the angle of regional differences, the growth rate of total factor of S\&T finance in eastern region, central region, western region and northeast region had some differences from 2015 to 2019, and the central region had the fastest annual growth rate of S\&T finance's TFP.

Based on the above research conclusions, the following policy suggestions can be made to improve the efficiency of S\&T finance. Firstly, we need to improve the scientific research system and mechanism, and enhance the input efficiency of human and material resources in the scientific research system. The empirical analysis shows that the internal expenditure of R\&D funds and fulltime equivalent of R\&D personnel are important investment indicators to measure the efficiency of S\&T finance, which also reflects that the investment of R\&D funds and manpower play an important role in the development of S\&T finance. Therefore, to increase the efficiency of science and technology finance, it is critical to improve the scientific research system and mechanism, promote scientific research achievements to be better transformed into market achievements, improve the mechanism and method of scientific research fund utilization, strengthen the quality construction of scientific research team, and then improve the input efficiency of scientific research manpower and material resources.

What's more, the government should play a leading and exemplary role in the development of S\&T and finance. Through the above empirical analysis of the measurement of S\&T finance's 
efficiency in 30 provinces and cities from 2015 to 2019, we can see that the government's policy support for S\&T finance has a positive effect on the efficiency of S\&T finance that cannot be ignored. Government policy support is also one of the important reasons for the high growth rate of TFP of science and technology finance in Henan, Guangdong and other regions from 2015 to 2019. Therefore, in the process of development of S\&T finance, it is especially necessary for the government to actively play its guiding and exemplary role and provide certain policy support and norms for the development of S\&T finance in this region. Strengthening the protection of S\&T property rights and improving the relevant laws and regulations on the protection of S\&T property rights are of great benefit to the development and improvement of the efficiency of S\&T finance.

Third, we should improve the S\&T financial market and enrich S\&T financial products. According to the decomposition results of the measurement of S\&T financial efficiency of 30 provinces and cities from 2015 to 2019 above, the scale efficiency index is at a low level among all indexes. Therefore, it is necessary to further improve the S\&T finance market, especially the S\&T finance element market, and enrich the forms and supply channels of S\&T finance products, so as to further improve the scale efficiency of S\&T finance. It is necessary to strengthen the strategic cooperation between S\&T innovation enterprises and insurance industry in the stage of enterprise science and technology innovation, encourage the establishment of insurance enterprises specializing in science and technology insurance, and provide further guarantee for the science and technology innovation of S\&T innovation enterprises.

\section{References}

[1] Hong. Science and Technology Finance and its Cultivation [J]. Economists,2011(06):22-27.

[2] Zhao, Chen and Tang. Science and Technology Finance. Science Press in Beijing,2009.

[3] Du, Liang and Lv. Research on the Efficiency of Regional Science and Technology Finance in China -Based on three-stage DEA Model Analysis [J]. Financial Economics Research,2016,31(06):84-93.

[4] Gan and Gan. An Empirical Study on the Efficiency Differences of Science, Technology and Finance in Bohai Rim, Yangtze River Delta and Pearl River Delta [J]. Macroeconomic Research,2017(11):103-114.

[5] Feng and Zheng. Heterogeneity Study on the Input-Output Efficiency of S\&T Finance of Small and Medium-sized Listed Enterprises based on the Common Boundary Dynamic DDF-DEA model [J]. Financial Theory and Practice,2021(02):39-51.

[6] Xue, Lin and Gao. Measurement and Analysis of Influencing Factors of Development Efficiency of S\&T finance in China [J]. Scientific and Technological Progress and Countermeasures,2017,34(07):109-116.

[7] Zhang and Gu. The Influence of S\&T finance on Regional Economic Growth: Based on Spatial Econometric Method [J]. Industrial Technical Economy, 2019,38(09):131-139.

[8] Zhang and Zhao. The Effect of China's S\&T Financial Input on S\&T Innovation: an Empirical Study based on Static and Dynamic Panel Data Model [J]. Scientific Research,2015,33(02):177-184+214.

[9] Charnes A, Cooper W W, Rhodes E. Measuring the Efficiency of Decision, Making Units[J]. European Journal of Operational Research, 1978, 2(6): 429-444.

[10] Pan and Zhang. The Innovation Performance of Government, Enterprises and Financial Institutions [J]. Scientific Research,2018,36(05):831-838+846.

[11] Gu and Wang. The Quality Effect of S\&T Financial Input on Economic Growth in China: a Spatiotemporal Heterogeneity Perspective [J]. Science of Finance and Economics,2018(08):30-43. 